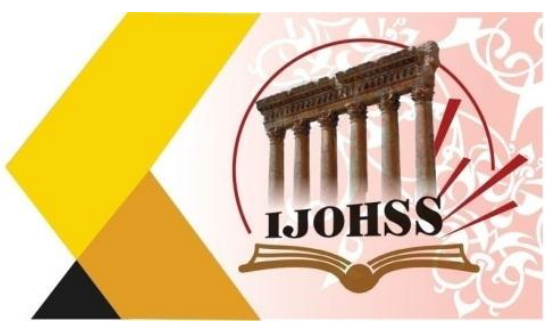

\title{
المظهر الإبداعيّ للاستعارة التصوريّة في نهج البلاغة
}

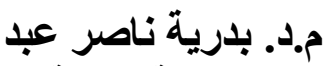 \\ قسم اللغة العربية \\ كلية الكوت الجامعة العربية

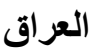

badrianaser@alkutcollege.edu.iq البريد الاككتروني:

الملخص

يضم العلم الإدر اكي (المعرفي) عدداً من النظريات التي تشترك في الأسس و المنطلقات ولكنها متداخلة في

بنائها المعرفي و اشتغالاتها وتوجهاتها ومجالات العناية فيها.

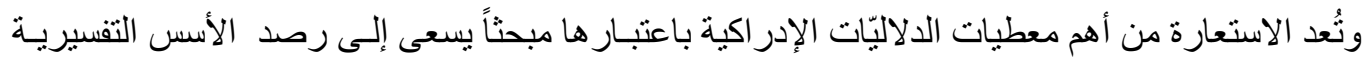

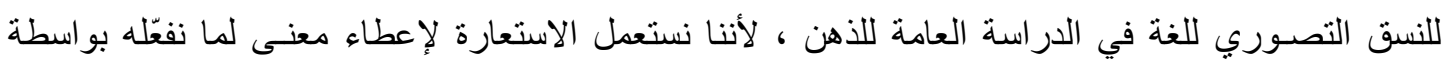
أذهانتا.

وقد تغيّت الدر اسة ربط التصور ات الاستعارية لـ (الموت و الدنيا و الدين و الدهر و الحرب) و غير ها بسياق

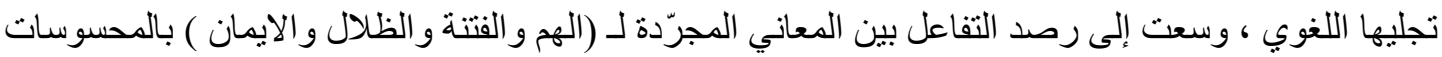
في ذهن الإمام علي عليه السلام وكيفيّة تصوّره لهذه المعاني ذهنيَّا.

الكلمات المفتاحية : الاستعارة التصورية، نهج البلاغة، العلم الإدراكي، الدلاليات الإدراكية، البنية التصورية،

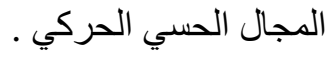




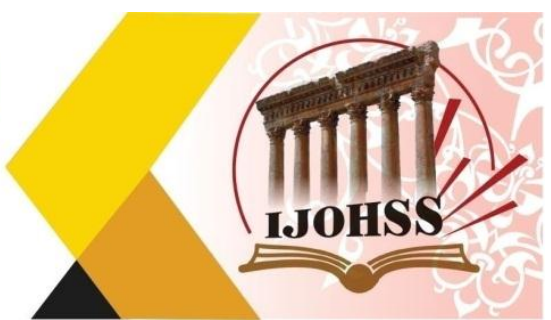

\title{
The Creative Appearance of the Conceptual Metaphor in Nahj Al- Balagha
}

\author{
Dr. Badriah Naser Abed \\ Department of Arabic \\ Al-Kut University College -Iraq \\ Email: badrianaser@alkutcollege.edu.iq
}

\begin{abstract}
In cognitive science, a number of theories have similar foundations and premises, but differ in their cognitive structure, orientations, and areas of interest .Because metaphor is one of the most significant cognitive semantics data as a topic that attempts to monitor the experience of the mind, we use it to explain the explanatory foundations of the conceptual system of language in the general study of the mind. because we utilize metaphor to provide meaning to our mental activities. The study looked at how abstract meanings like (worship, sedition, shadows, and faith) interact with sensible items in Imam Ali's mind, and how he mentally interpret these meanings.
\end{abstract}

Keywords: Cognitive science, Cognitive semantics, conceptual structure, sensorimotor domain. 
العدد (30)

Volume (30) February 2022

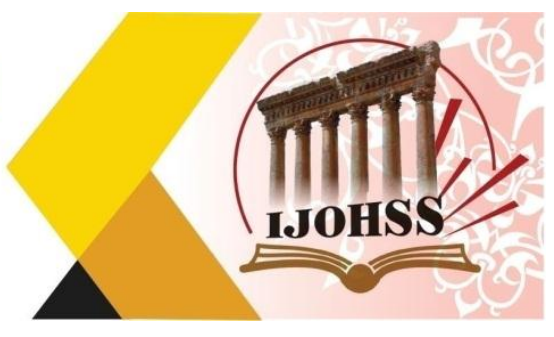

ISSN: $2415-4822$

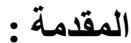

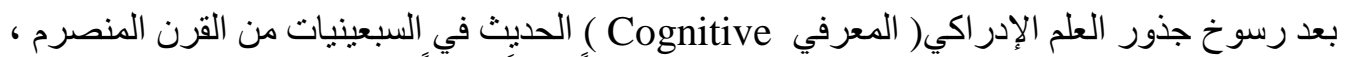

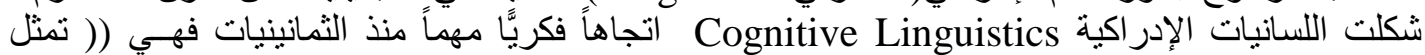

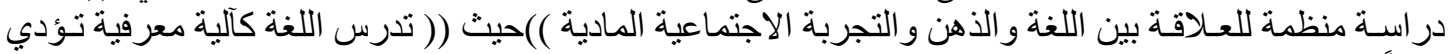

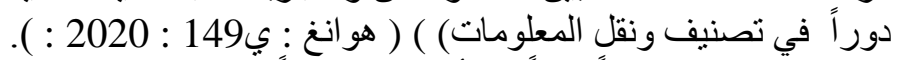

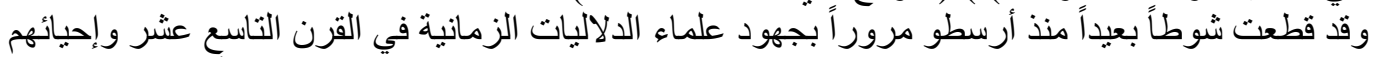

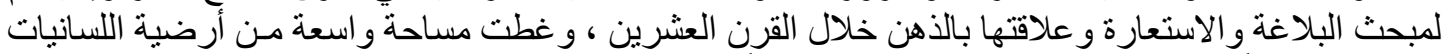

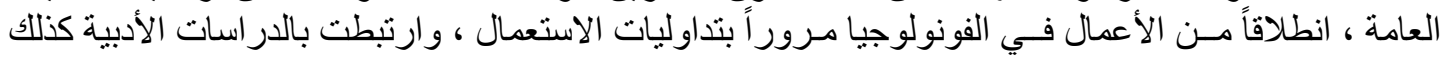

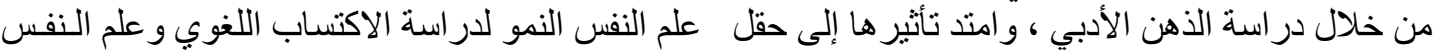

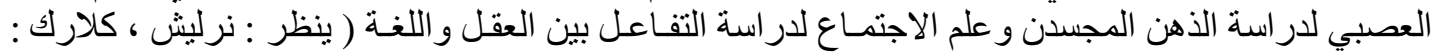
285 :2017، وبوبوفا وستيرنين : 14 : 14 : 2012 ). وتعدُّ الدلاليات الإدر اكية Cognitive semantics : المحور الأهم الذي قامت علئ عليه اللسانيات الإدر اكية ،

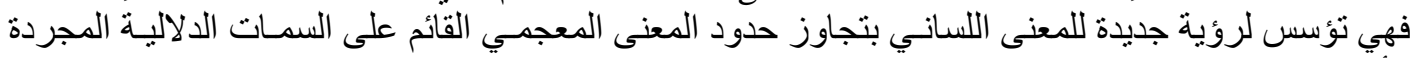

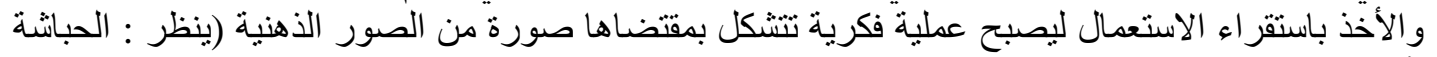

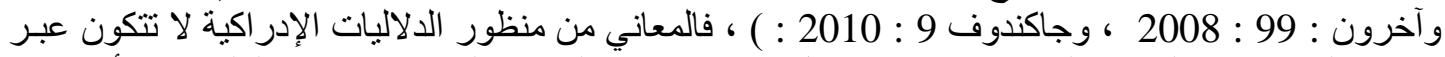

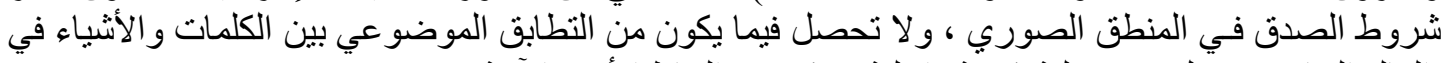

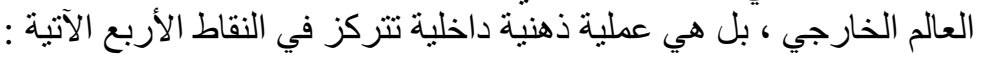
ـ الإدر الك المعرفي مجسّّ. ـ - البنية الدلالية تعكس البنية التصورية.

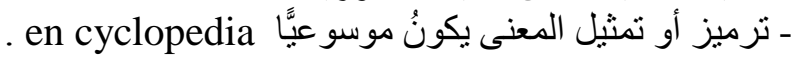

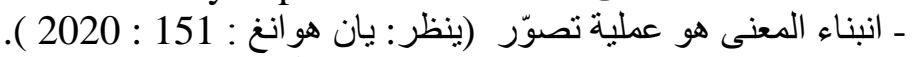

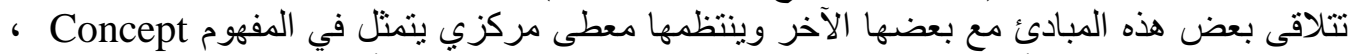

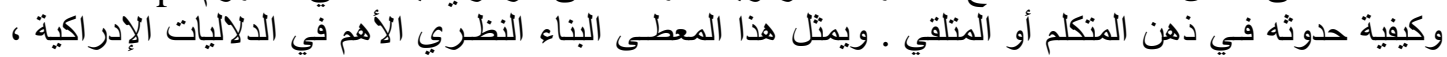

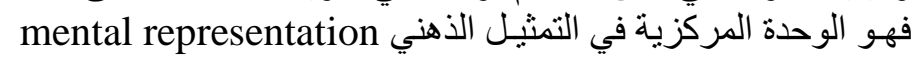

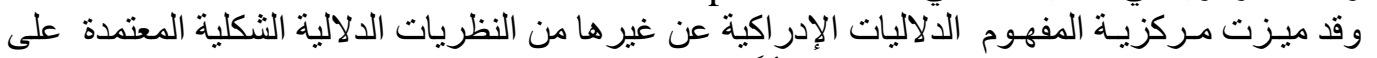

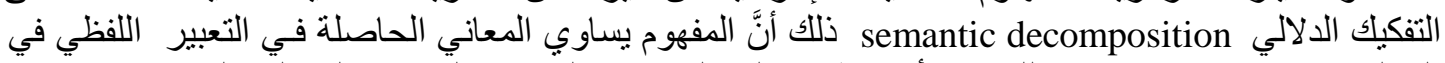

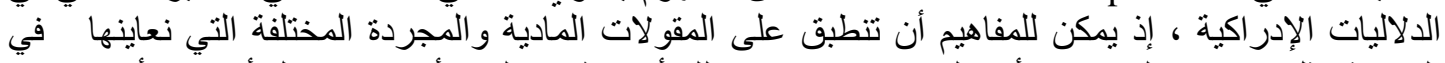

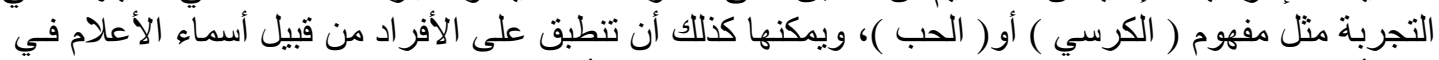

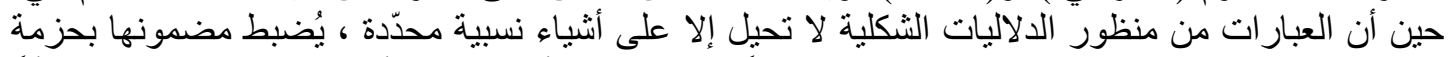

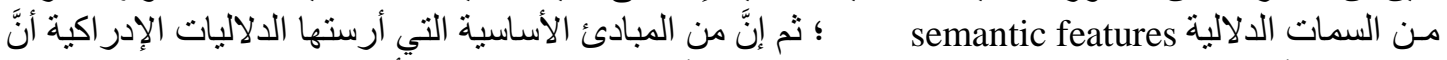

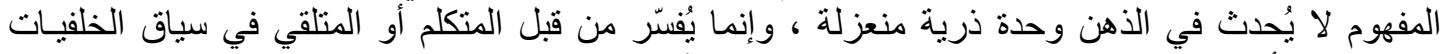

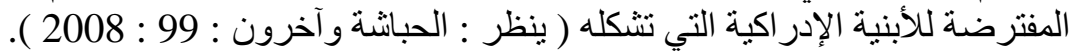

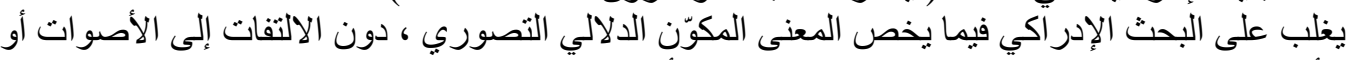

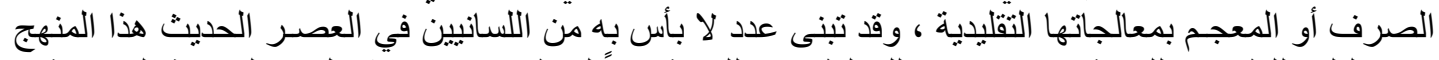

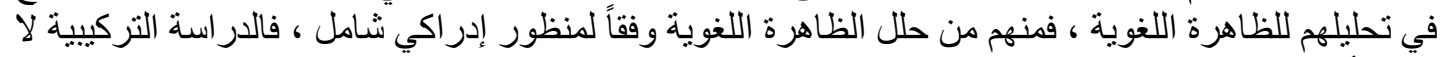

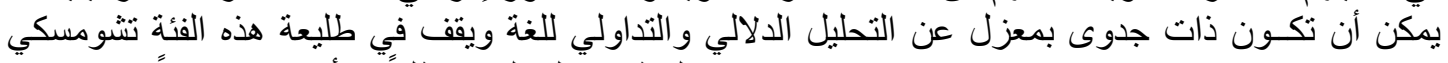

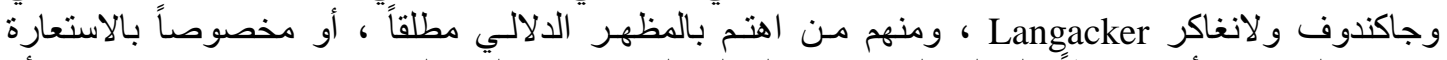

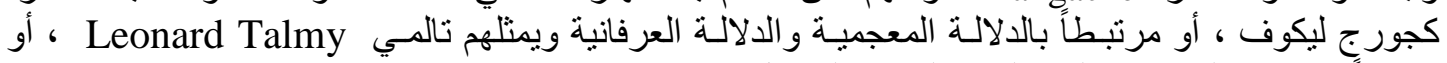

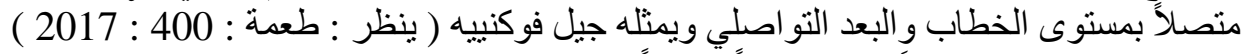

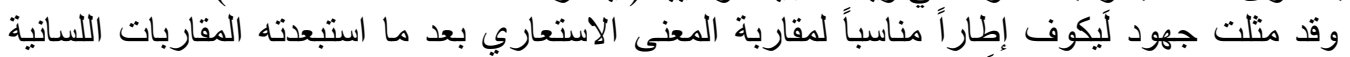

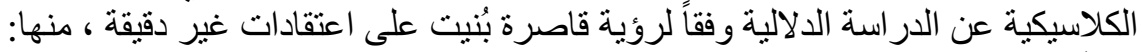
ـ ـ أنَّ الاستعارة تتعلق بالألفاظ ، و هي بعيدة كل البعدة البعد عن الفكر. 
العدد (30) فبراير 2022

Volume (30) February 2022

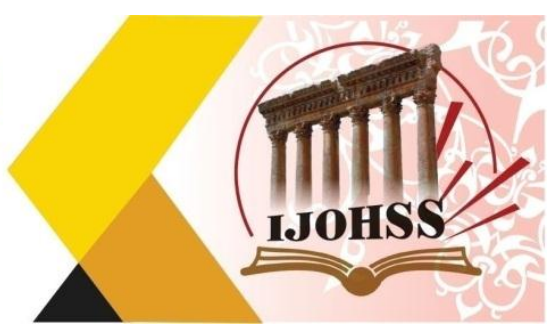

ISSN: $2415-4822$

ـ ـ اللغة الاستعارية تقتصر على الشعر و الدر اسات البلاغية.

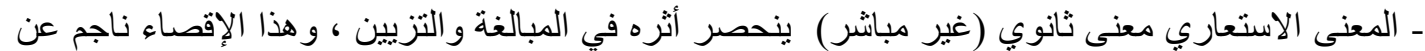

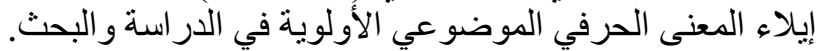

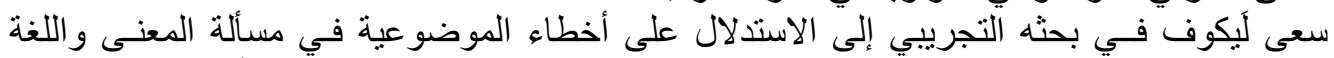

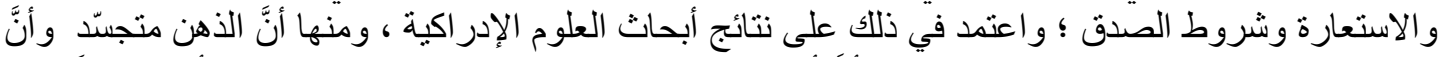

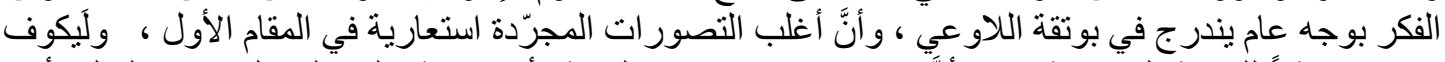

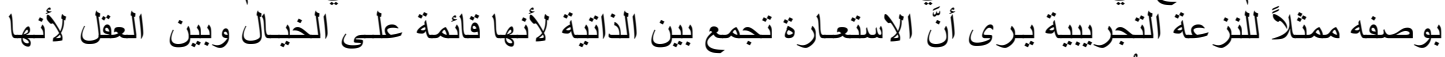

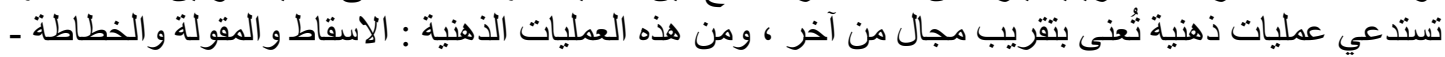
الصورة(ينظر : مصمودي دهنئ : 2017 :

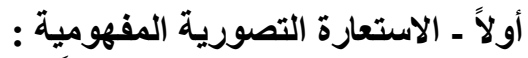

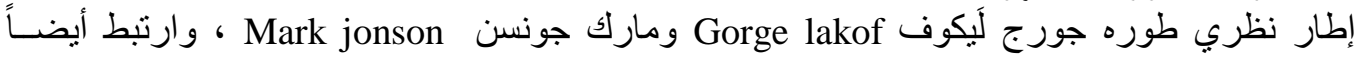

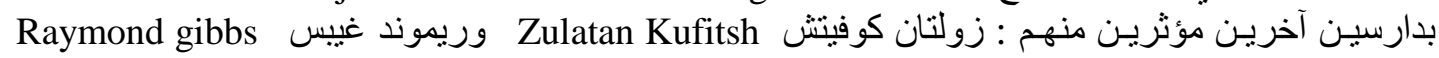

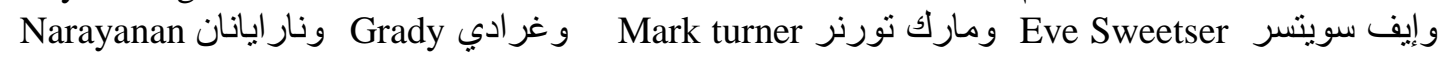

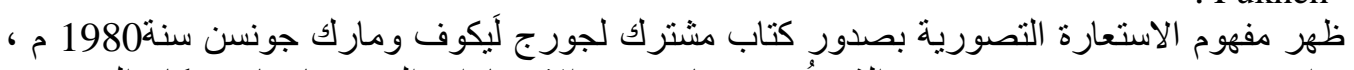

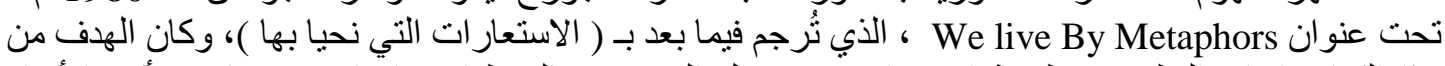

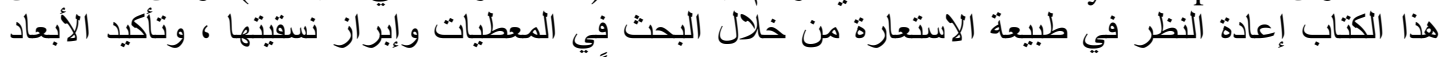

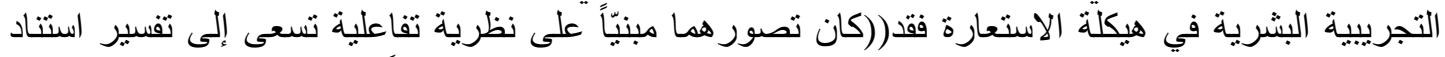

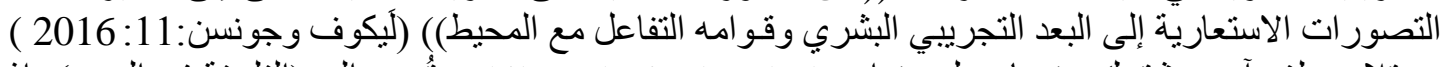

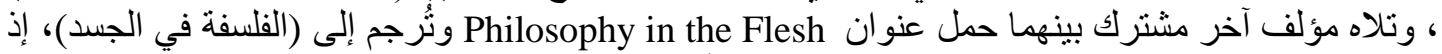

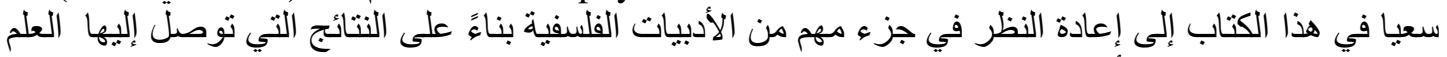

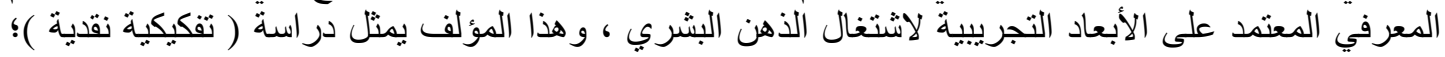

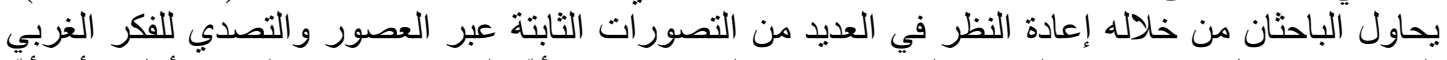

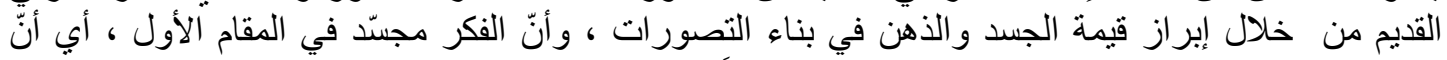

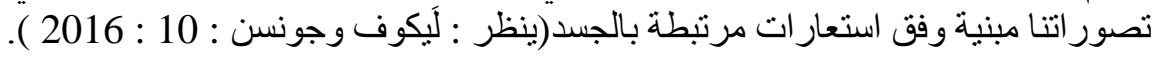

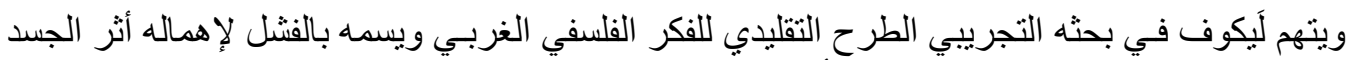

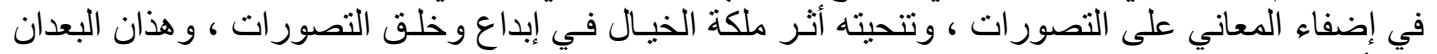

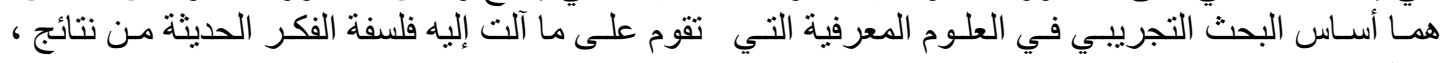
1- أنّ العمليات الذهنية المعرفية ( الإدر اكية)تعتمد على العقل وقدرته على الاستنتاج و الاستدلال و النقد و التقويم

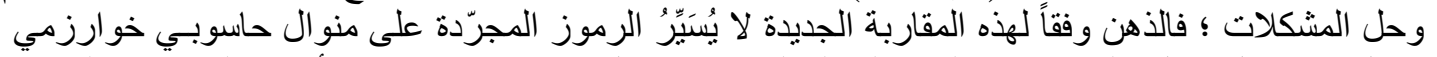

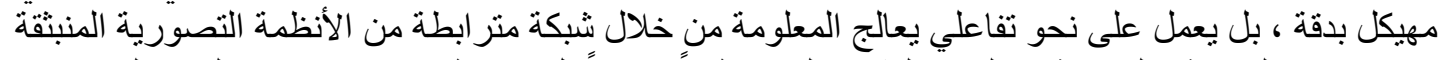

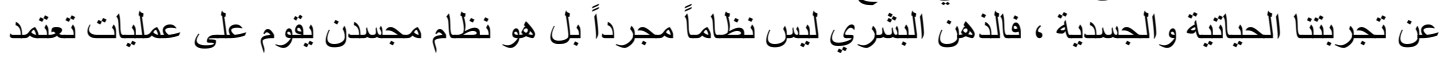

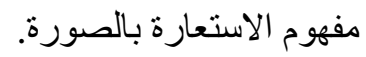

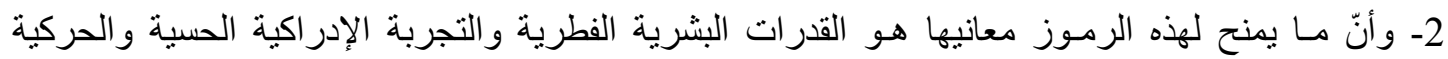

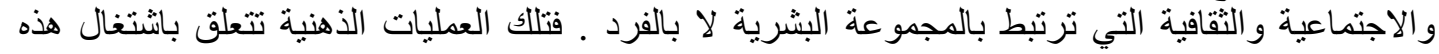

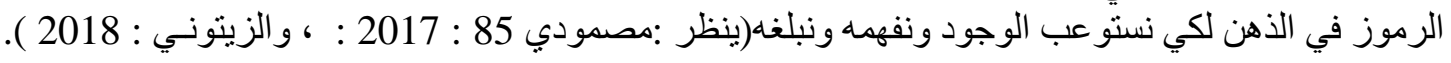


العدد (30) فبراير 2022

Volume (30) February 2022

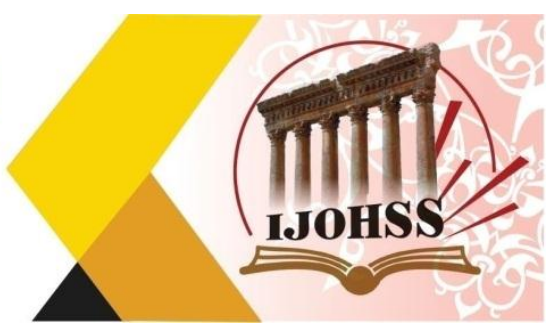

ـ Embodiment التجسد أو الجسدنة

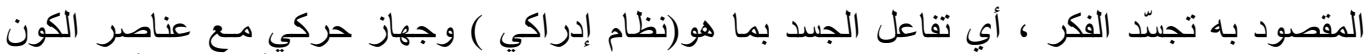

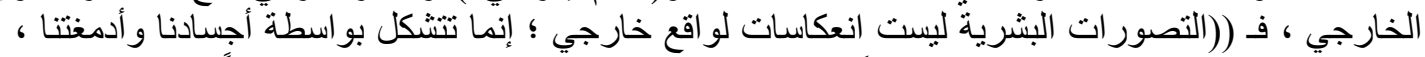

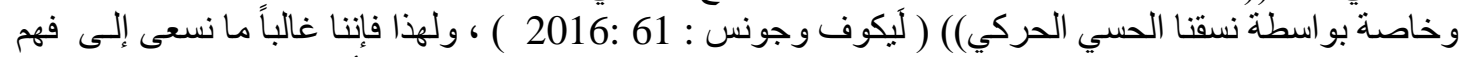

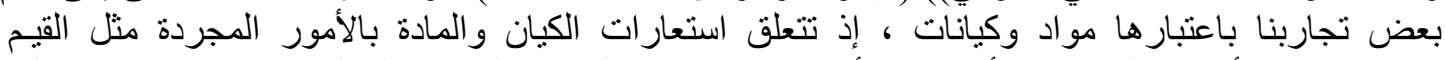

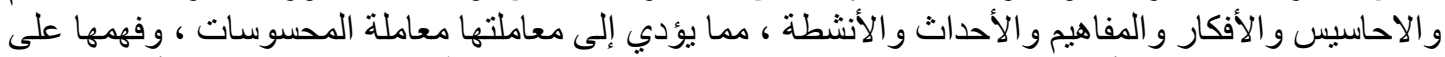

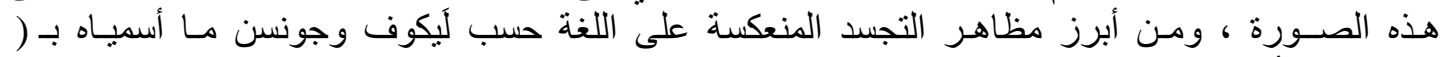

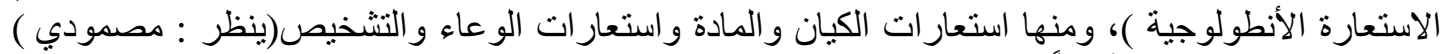

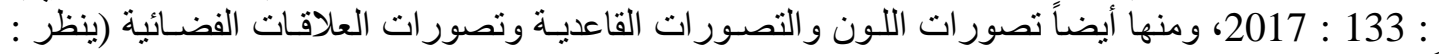

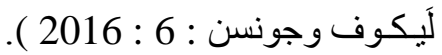
- الأساس التجريبي للتصور :

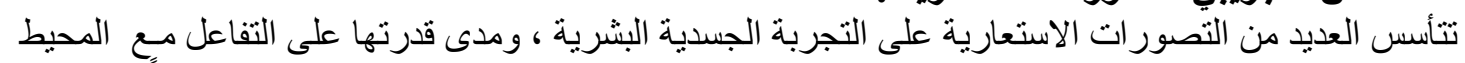

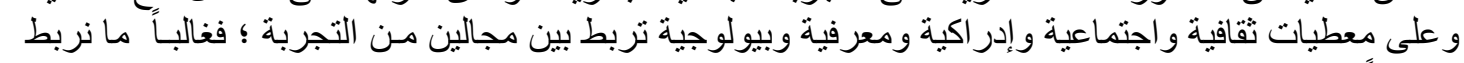

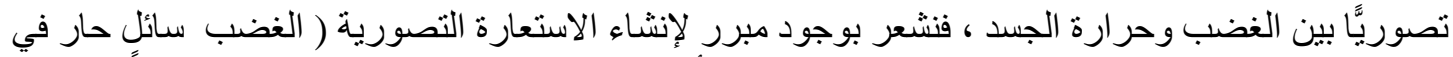

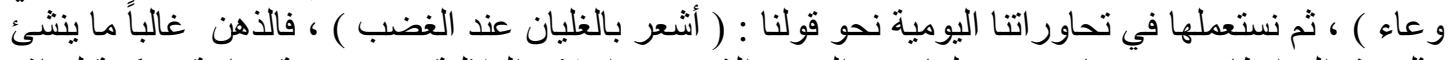

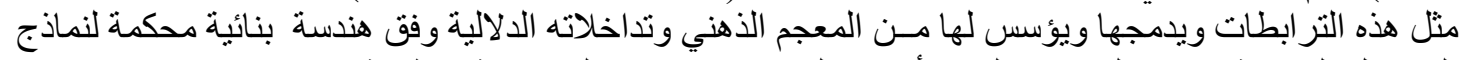

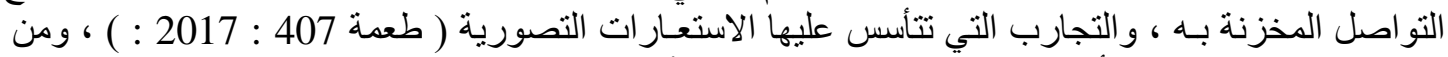

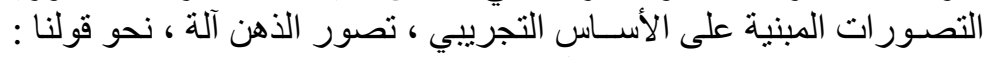
ـ - عقلي غير قادر على العمل الآن. ـ ـ لقد أصناب الصدئ عقله.

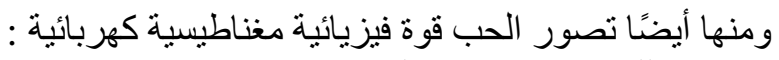

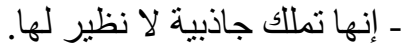

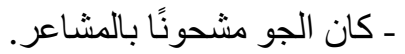

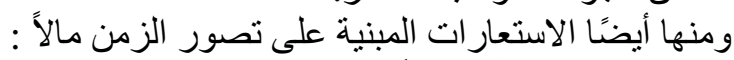

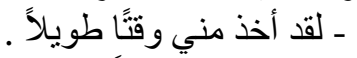

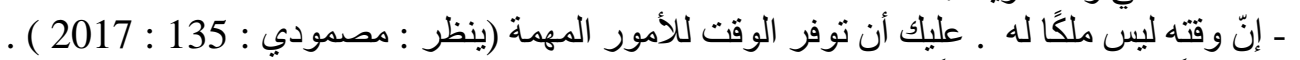

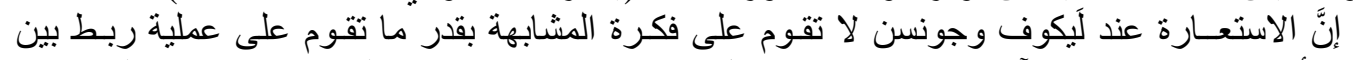

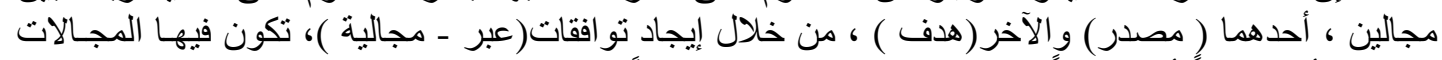

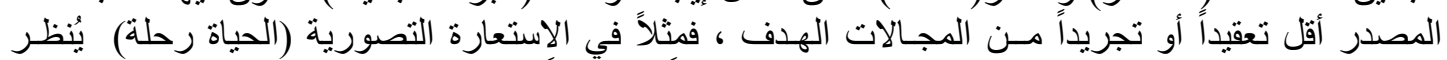

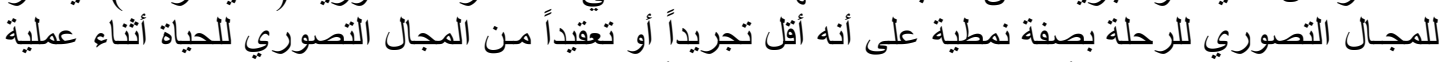

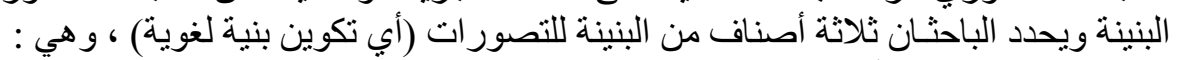

1 الاستعارات البنيوية Structural metaphor

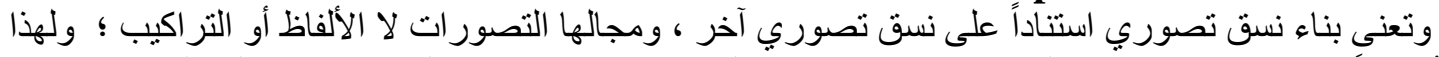

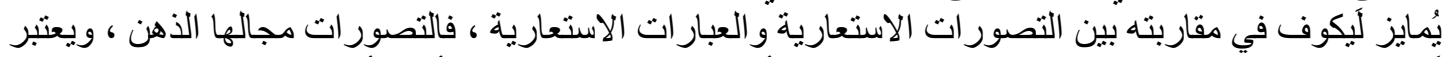

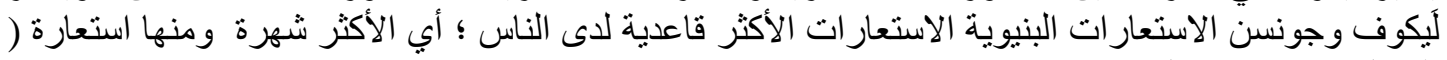

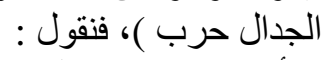

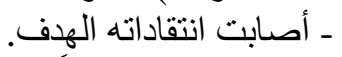

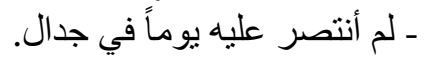

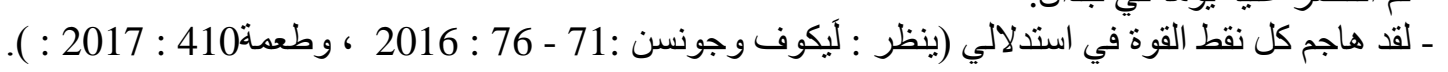


العدد (30) فبراير 2022

Volume (30) February 2022

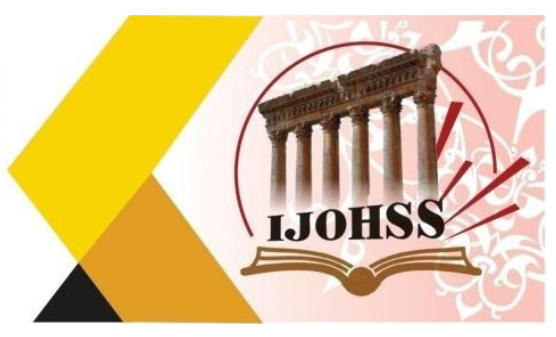

2- الاستعارات الاتجاهية orientational metaphor

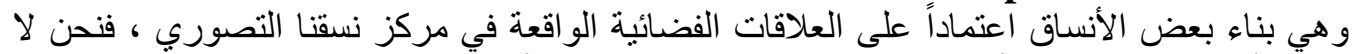

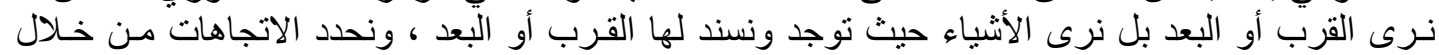

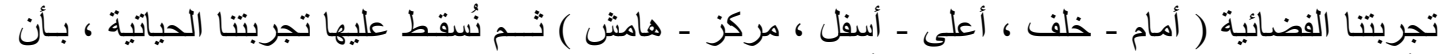

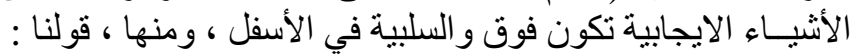

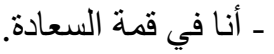

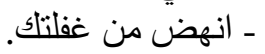
ـ ستظل في القاع دائماً ( بنظر : لَيكوف وجونسن :71 - 76 : 73 : 2016 ، ومصمودي- 147: 118 : 2017 : . (120: 134 - 133

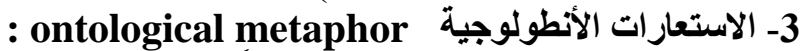

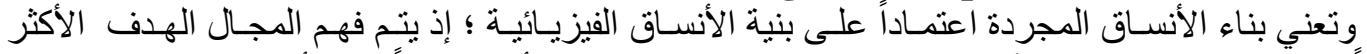

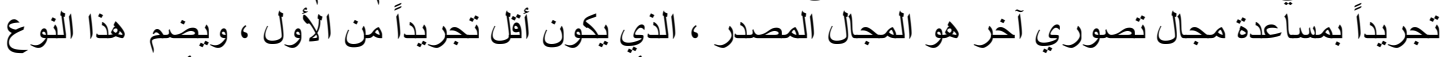

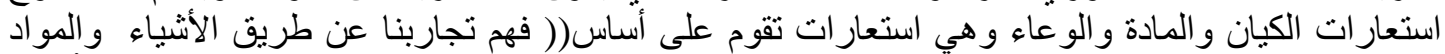

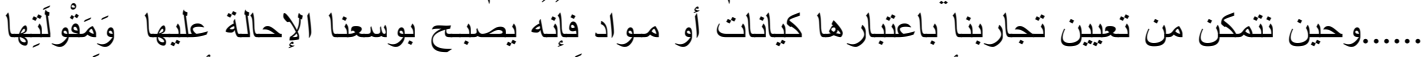

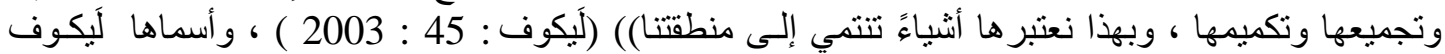

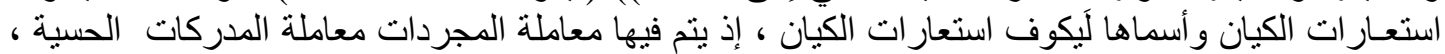

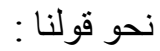

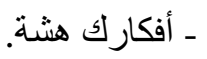
ـ ماح خبرك بالمدينة.

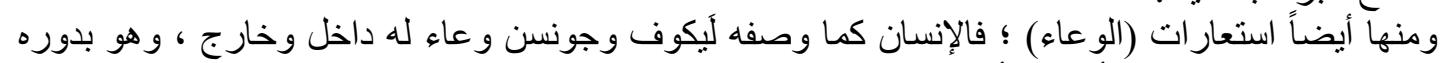

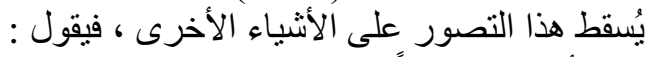

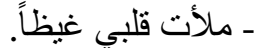
ـ انساب من فمه كلام كالثهد (ينظر : مصمودي : 133 - 134 : 134 : 2017 ).

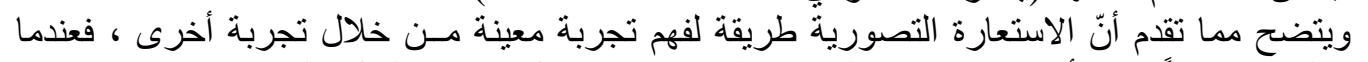

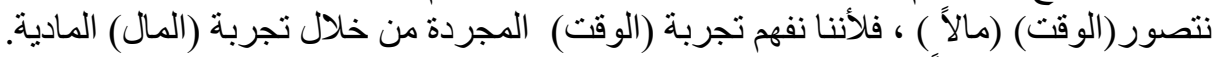

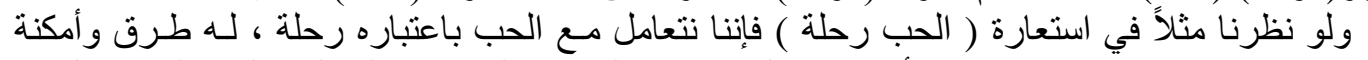

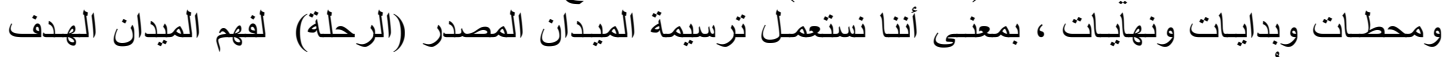

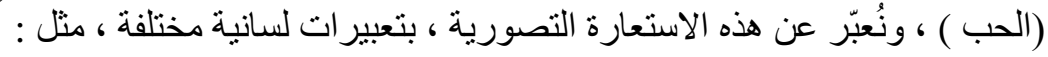

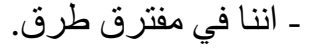

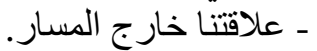
- إنـا لا نستطيع أن نعود الآن. - إنّ العلاقة لن تصل بنا إلى بر الأمان (ينظر : لَيكوف : 12 : 2014 ولَيكوف وجونسن - 115 : 2017 :

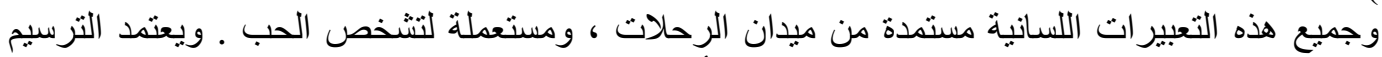

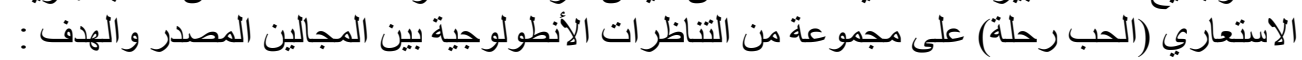

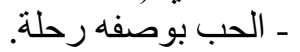

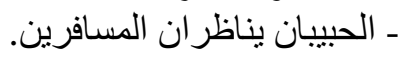
ـ علاقة الحب تنتانر المركبة.

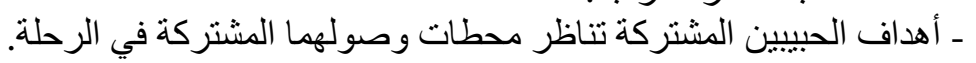

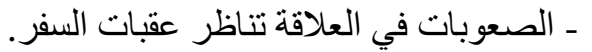




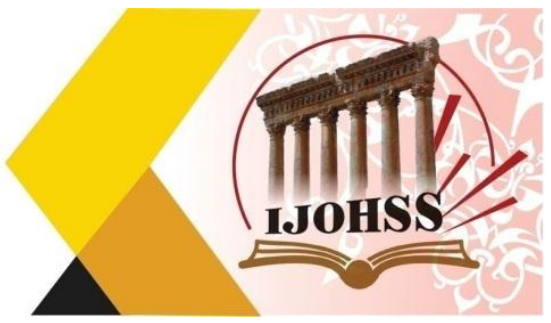

في استعارة الحب رحلة تصبح أهداف المتحابين المشتركة في الحياة وجهات ، و المتحابان مسافر ان ، وما

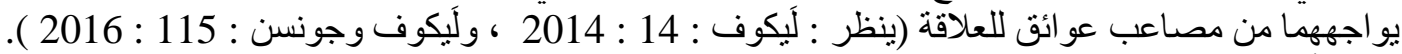

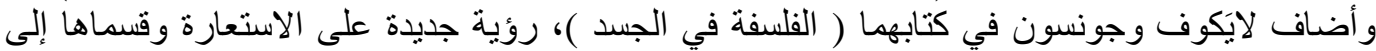

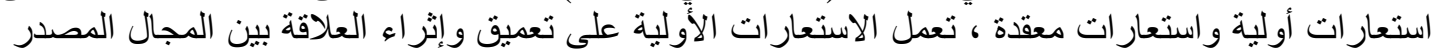

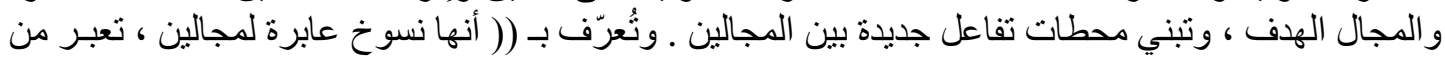

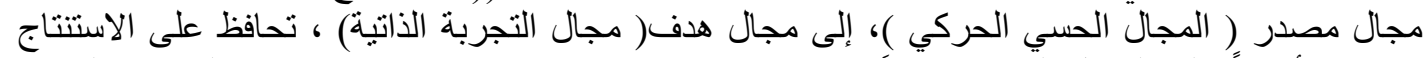

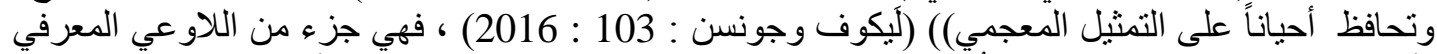

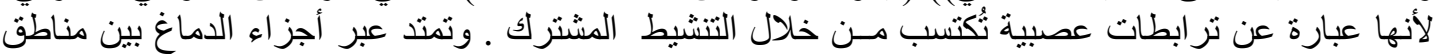
التجربة الحسية الحركية ومناطق التربة التجربة الذاتية.

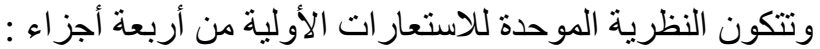

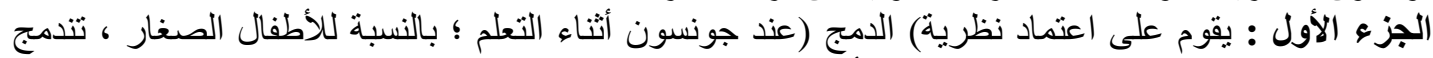

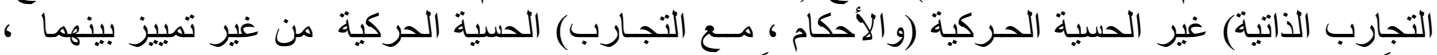

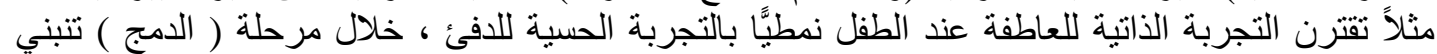

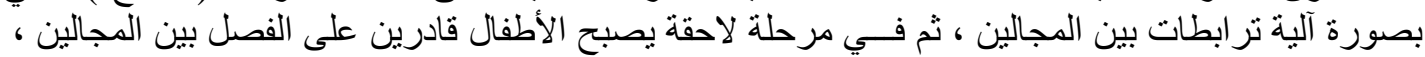

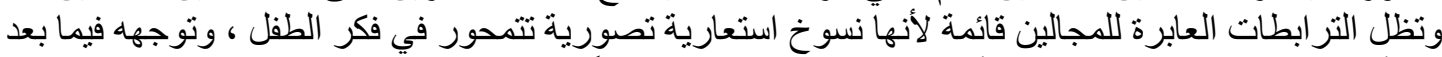

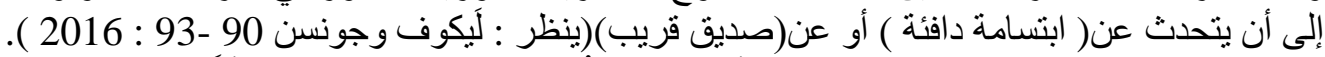

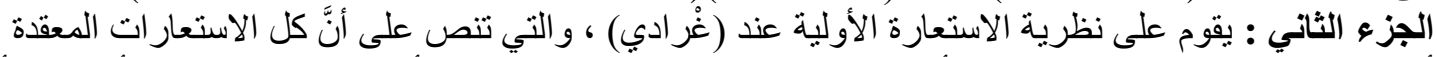

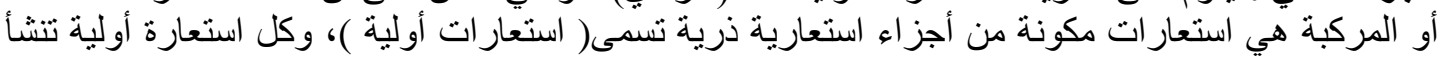

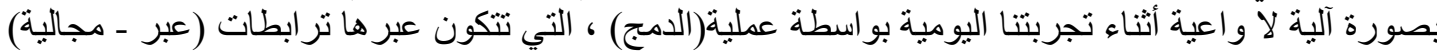
، ومـن ثمة تتكون الاستعار ات المعقدة بواسطة نظرية (المزج التصوري)(ينظر : ليكوف وجونسن : 2016 ). $91-90$ :

الجزء الثالث : يعتمد على النظرية العصبية للاستعارة عند نار ايانان (إنَّ الترابطات التي تحصل خلال مرحلة

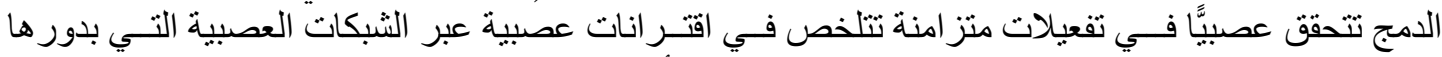

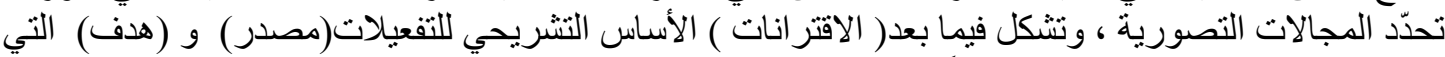

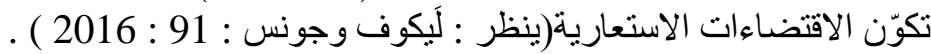

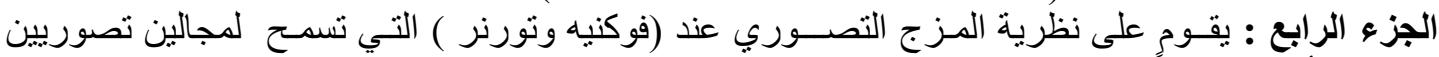

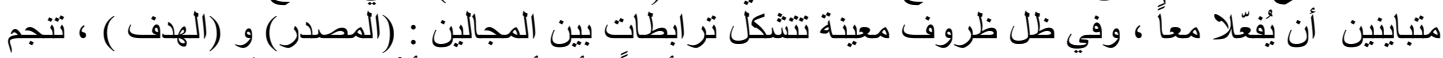

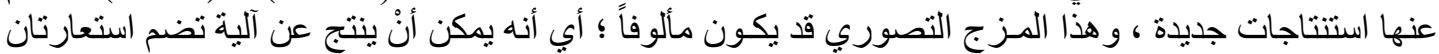

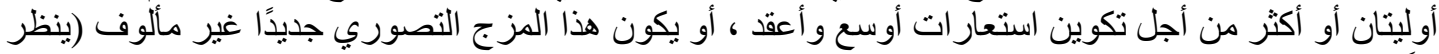

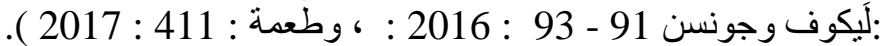

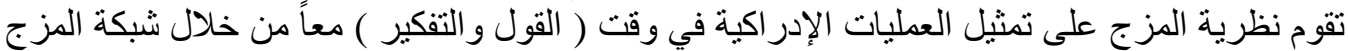

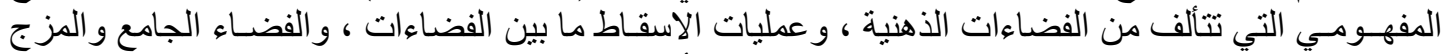
و الاسقاط الانتقائي و التركيب ، و الإتمام ، و البلورة ، ثم تنشأ البنية الجديدة (طعمة : 411 : 2017 ).

ثانياً ـ الاستعارات التصورية في نهج البلاغة :

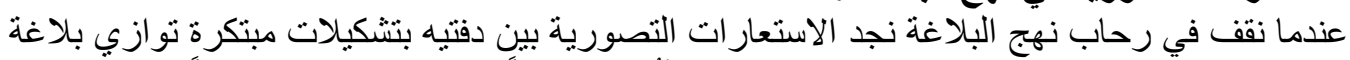

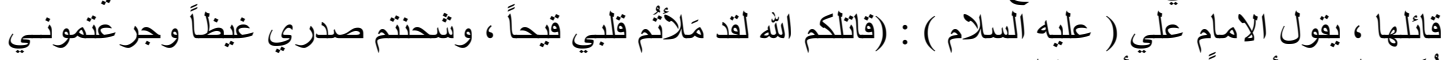

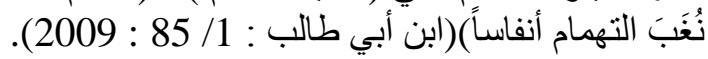

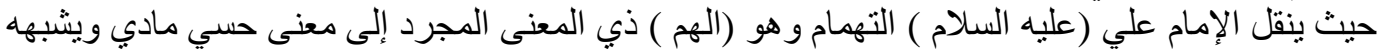

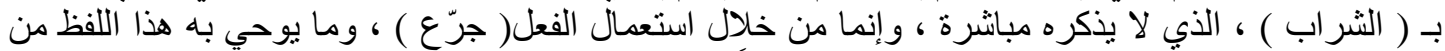

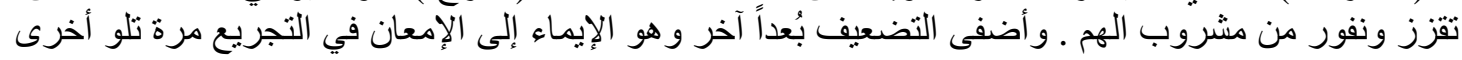




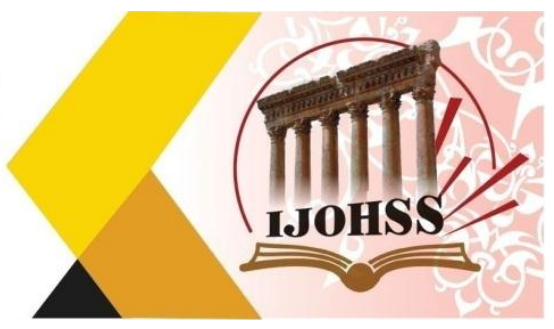

(ينظر : أقدم ، كارخانة 326 : 2018 : : ) ، ثم تأتي الاستعارة الثانيةً أنفاساً لتصف لنأ أنا مالقيه الامام علي (عليه

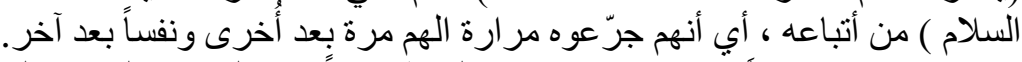

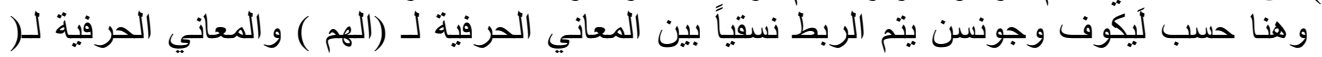

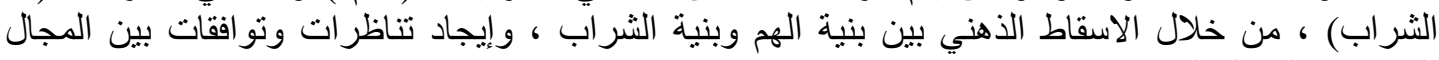

المصدر و المجال الهدف : المن :

(المجال المصدر ) المجال الحسي الحركي (المجال الهدف) مجال التجربة الذاتية

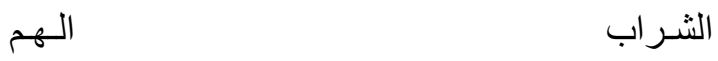

وتتهض هذه التناظر ات بين المجالين (المصدر) و(الهدف ) بتشكيل المشابهة الملائمة بين المجالين اعتماداً

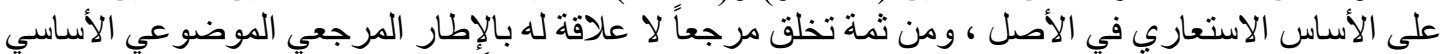

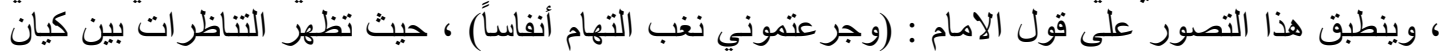

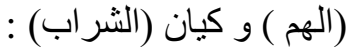

جدول (1)

\begin{tabular}{|c|c|}
\hline المجال الهُف & المجال المصدر \\
\hline التقله على النفس قلب المهموم & 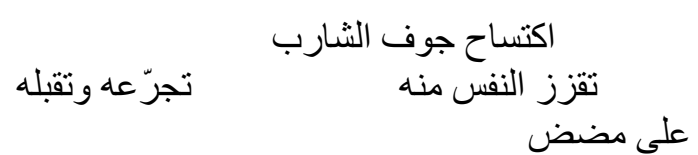 \\
\hline
\end{tabular}

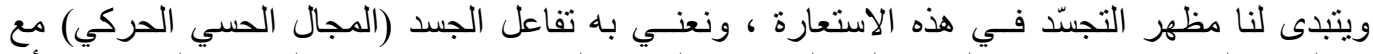

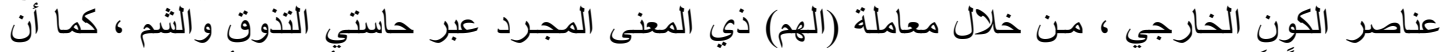

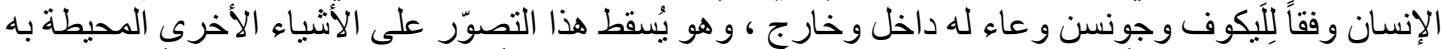

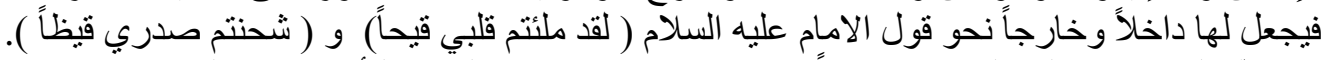

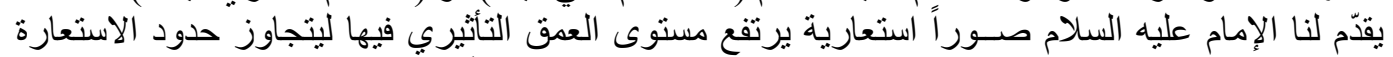

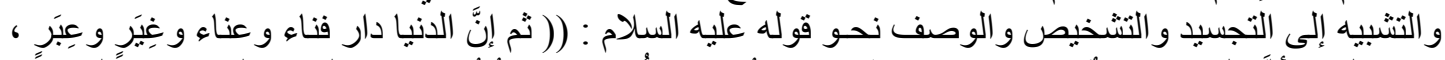

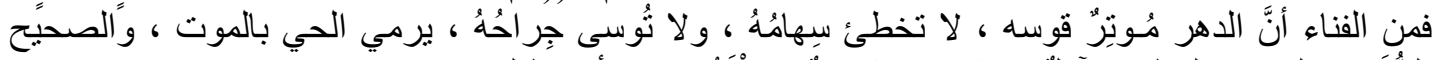

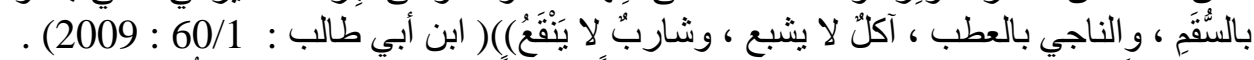

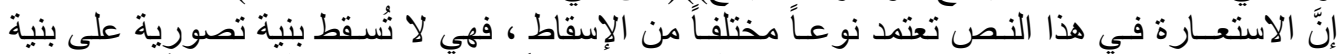

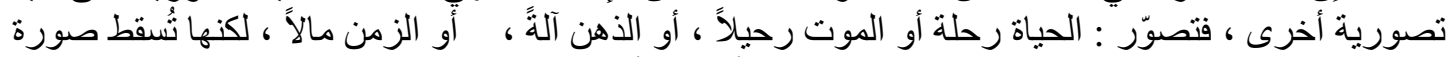

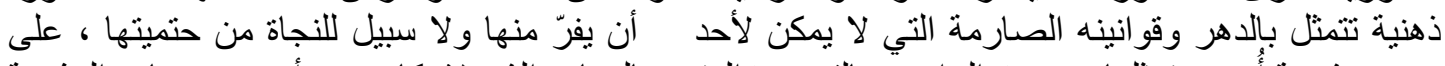

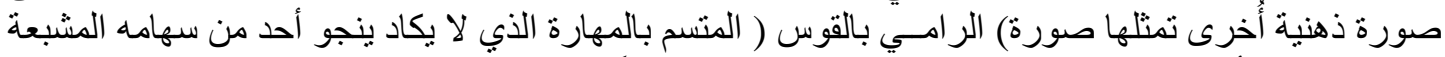

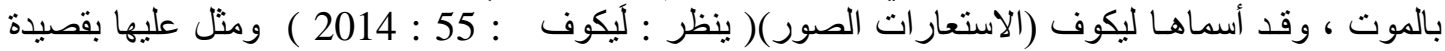

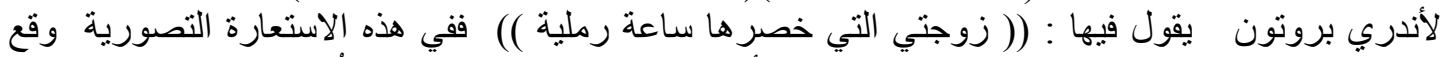

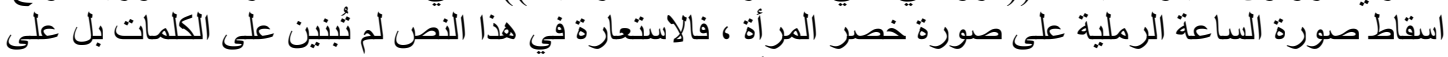

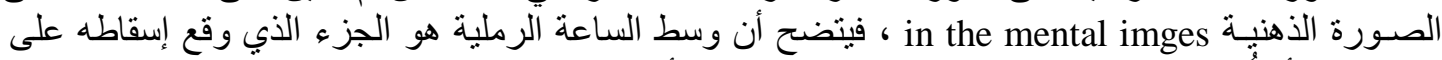

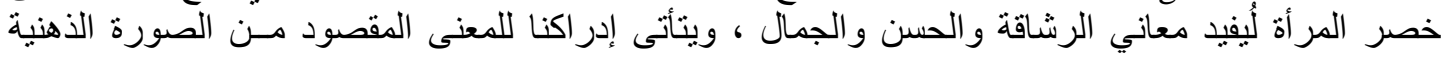




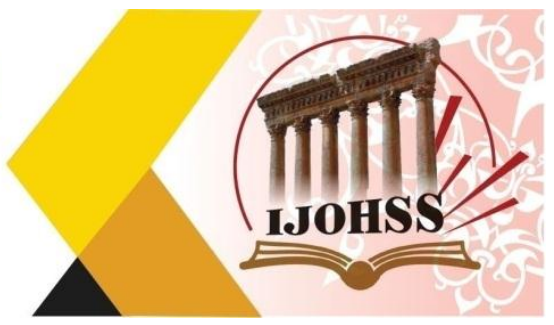

المألوفة لدينا عن السـاعة الرملية ، ويستند هذا النوع من الاسقاط في الاستعارات الجديدة إلى عنصري ( الخيال

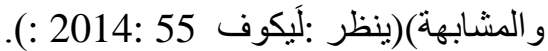

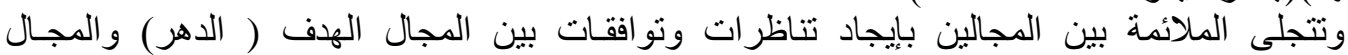

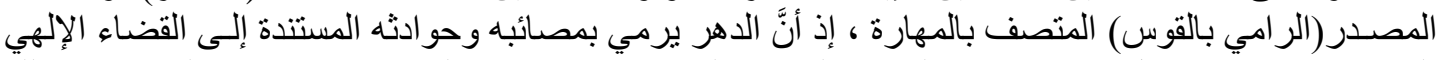

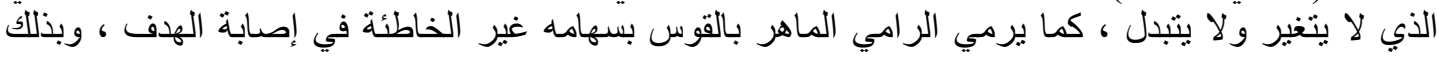

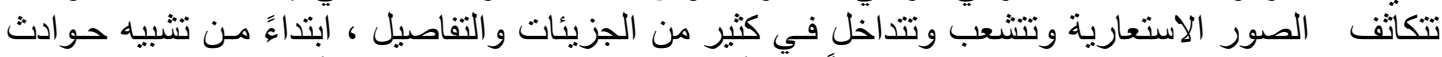

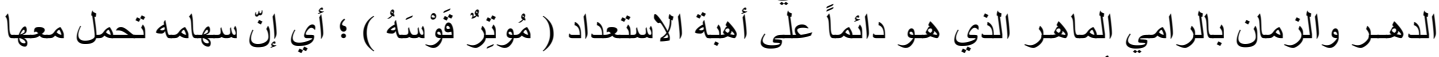

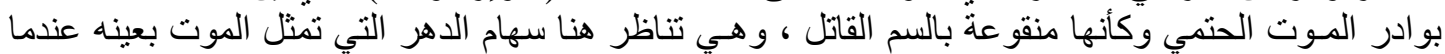

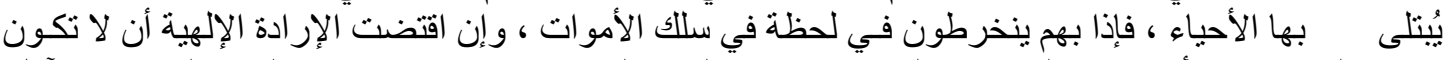

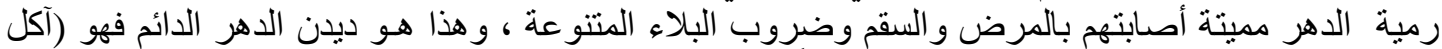
نهم) لا سبيل لثبعه ، متعطش أبدي يتقد جوفه نار أ لا سبيل إلى إطفائها.

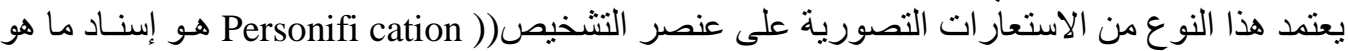

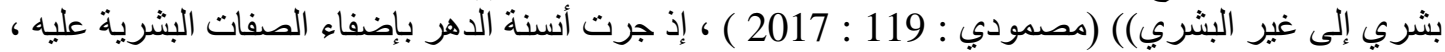

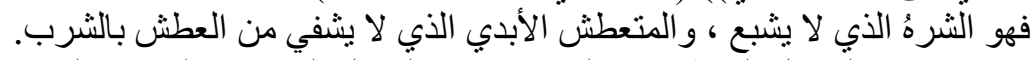

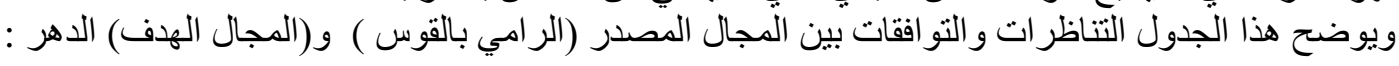

\section{جدول (2)}

\begin{tabular}{|c|c|}
\hline المجال الهذف (الدهر) & المجال المصدر (الرامى بالقوس) \\
\hline حو ادث الدهر تأتي على حين غفلة & يعتمد الرامي الماهر على عنصر المباغتة \\
\hline حو ادث الدهر تقضي على الانسان وتصييه بالمصائب & سهام الر امي تصيب الانسان بالجر اح و الموت \\
\hline 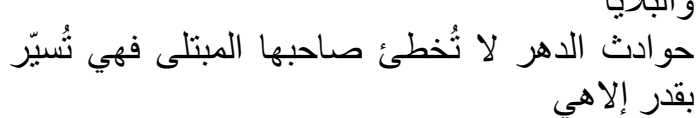 & المهارة في التسديد ، فالسهم لا يخطئ الهدف \\
\hline
\end{tabular}

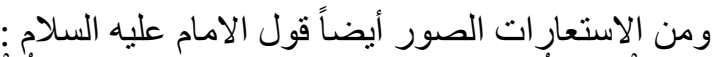

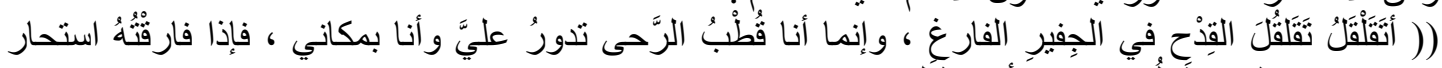

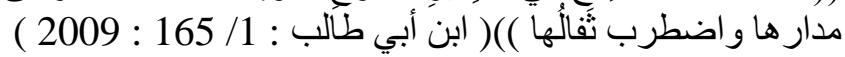

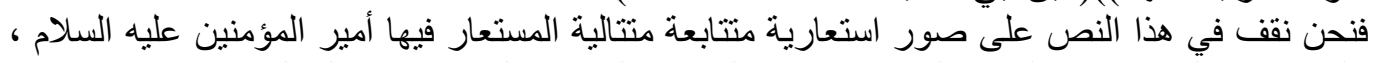

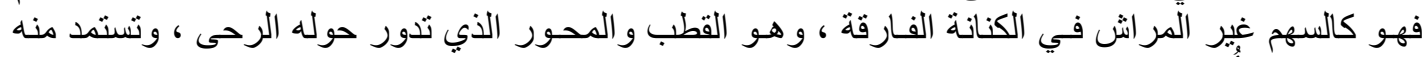

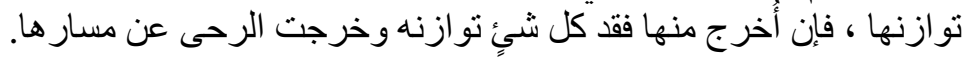

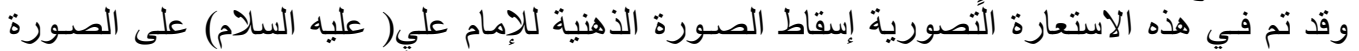

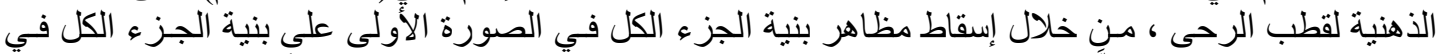

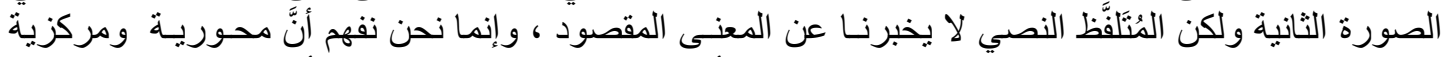

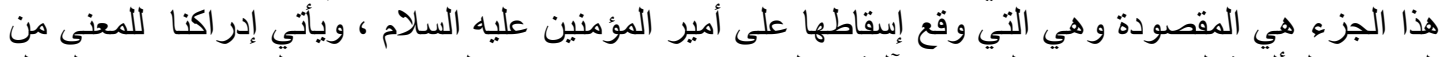

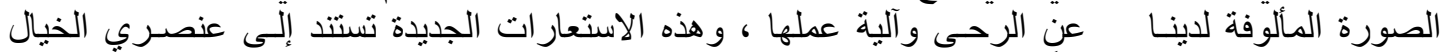
و المشابهة التي ذكرناها سابقاً.

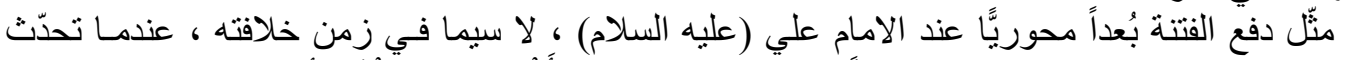

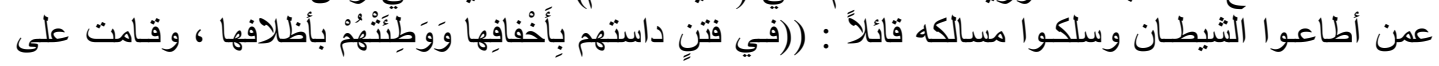


العدد (30) فيراير 2022

Volume (30) February 2022

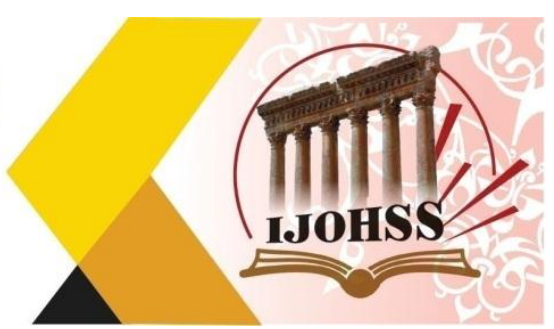

سنابكها ، فهم فيها تائهون ، حائرون ، جاهلون ، مفتونون ، في خير دارِ وشـرٍِ جيرانٍ )) (ابن أبي طالب : . $2009: 30 / 1$

إذ نرى الإمام علي ( عليه السلام ) يُسند الفعلين (داست ) و (وطئت) إلى الفتن ويُغيّب الهوية الموضو عية

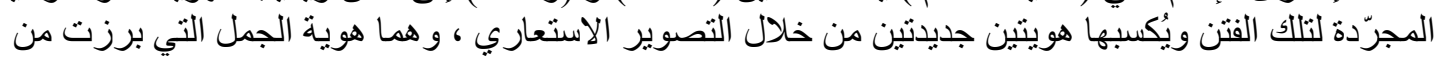

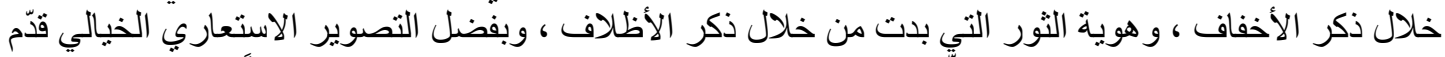

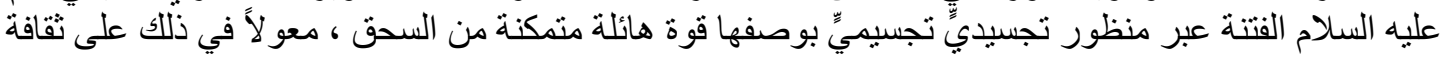

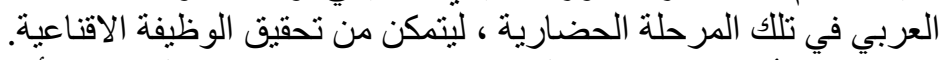

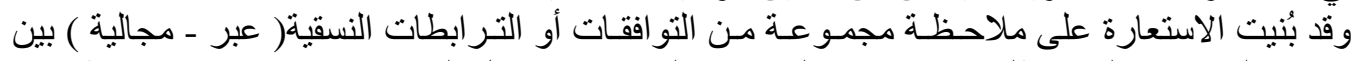

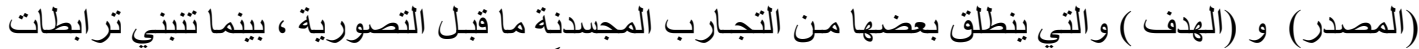

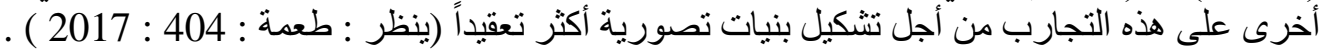

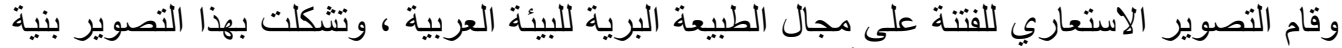

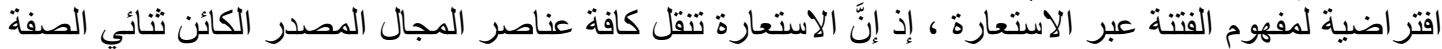

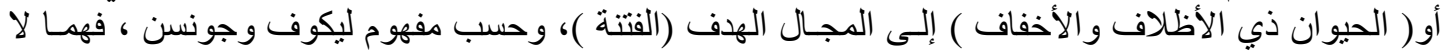

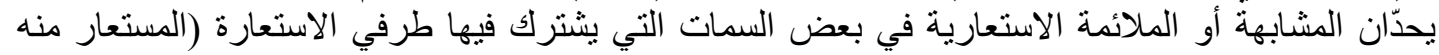

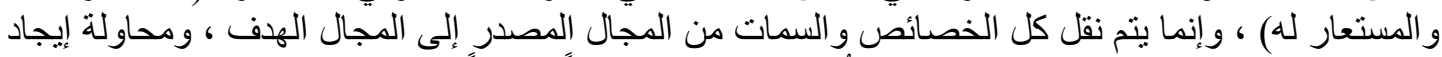

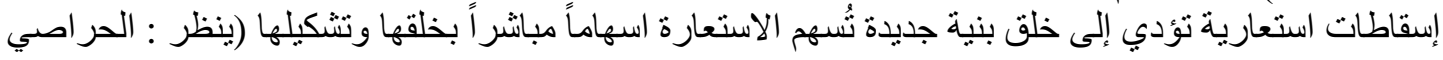
: (2003 : $147-146$

ونجد الإمام عليه السلام في العديد من مأتور كلامه بستثمر التصوير الاستعاري لئتئر قضايا ذهنية

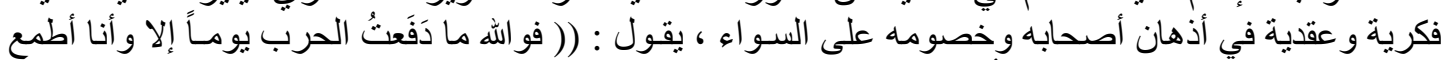

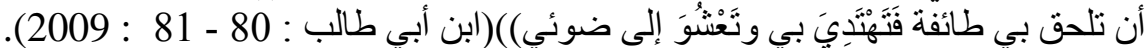

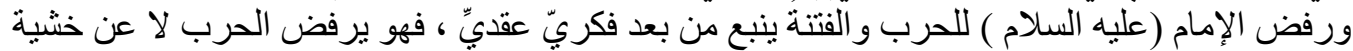

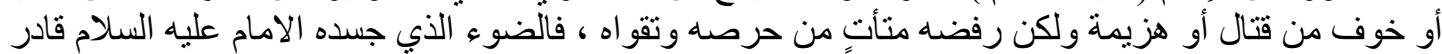

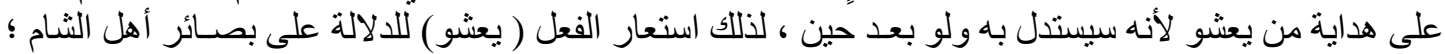

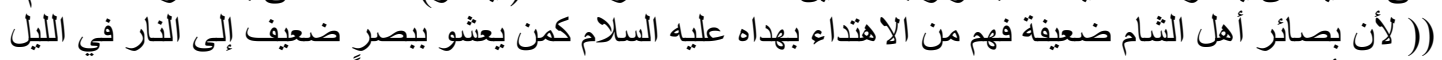

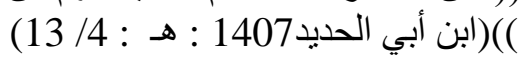

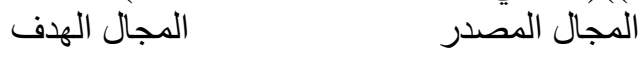

وتم هنا توظيف المجال الحسي الحركي المتمثل بـ ( الضوء) أو النار للوصول إلى مجال التجربة الذاتية وهو(

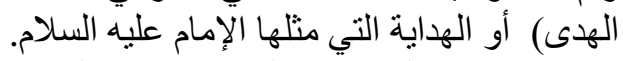

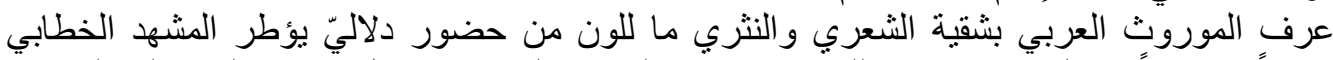

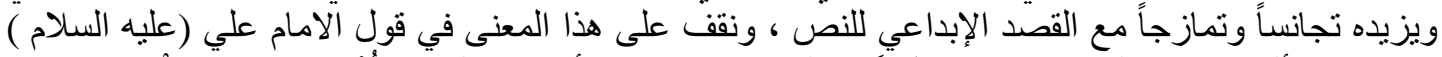

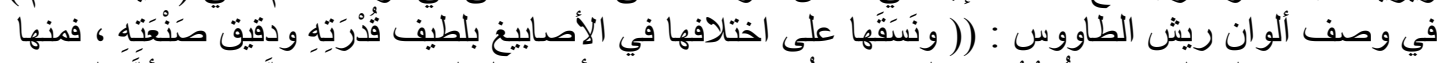

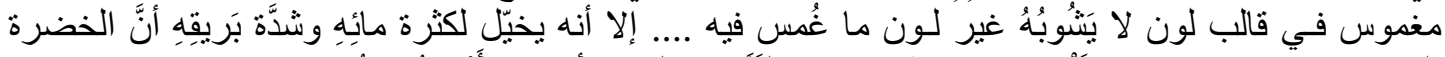

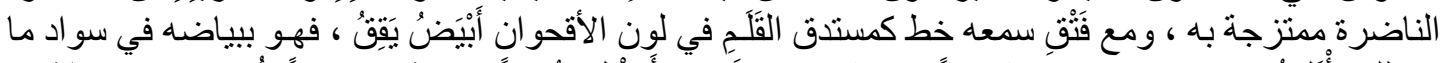

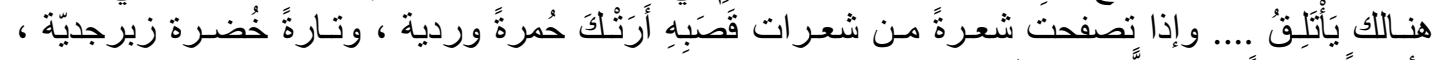

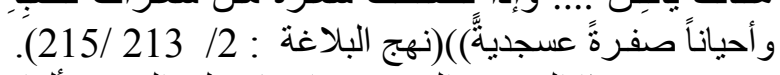

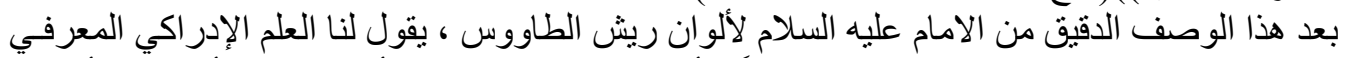

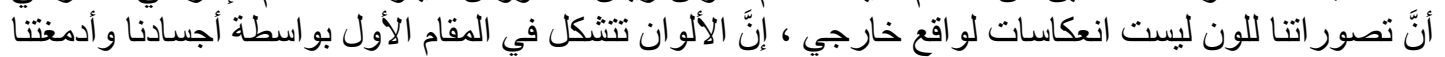

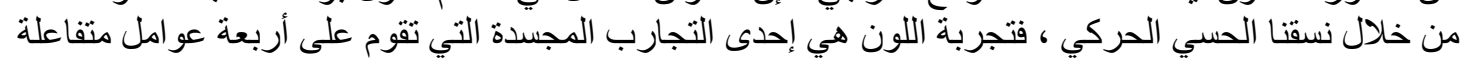




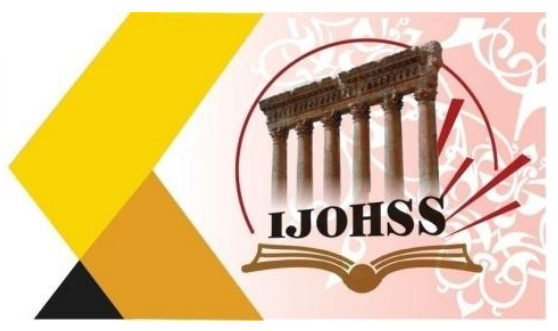

فيما بينها وهي : ((ظروف الإضاءة ، الطول الموجي للإشعاع الكهرومغناطيسي ، تدرجات اللون وعمل

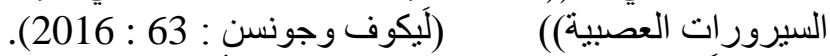

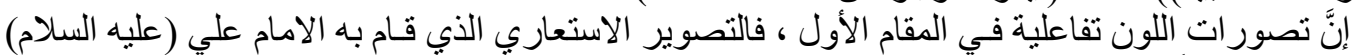

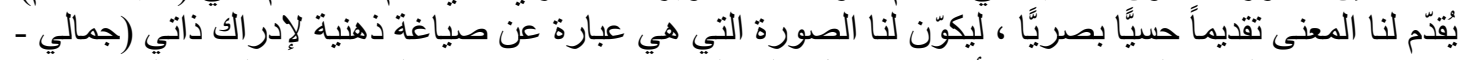

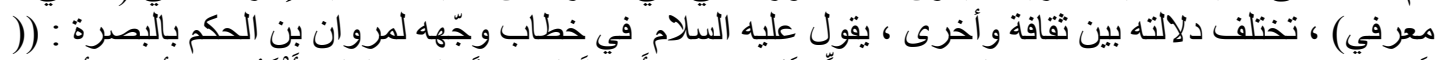

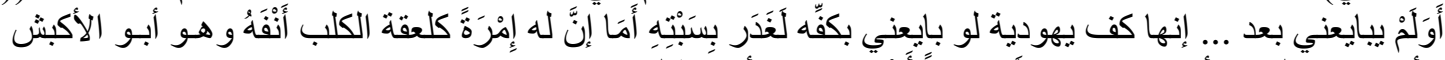

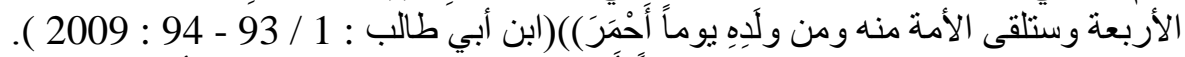

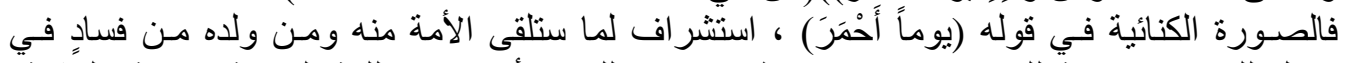

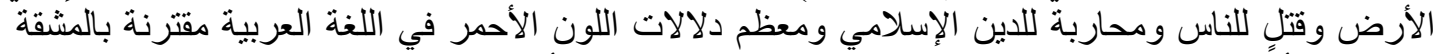

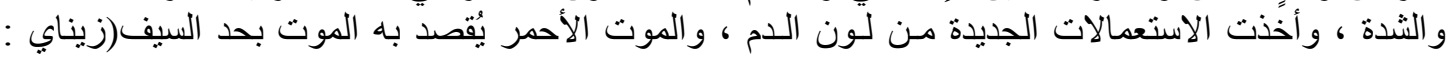
.)(2021: 54

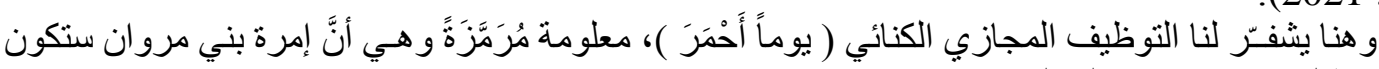
جائرة ظالمة تسنبيح دماء المسلمين.

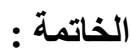

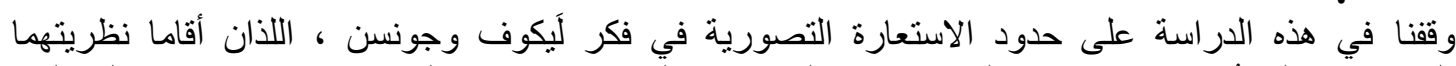

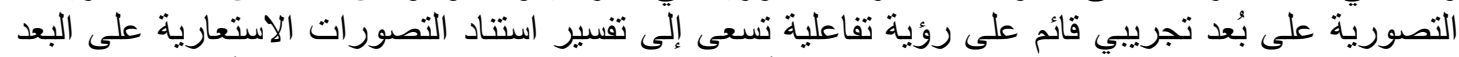

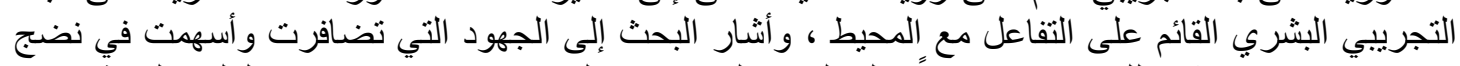

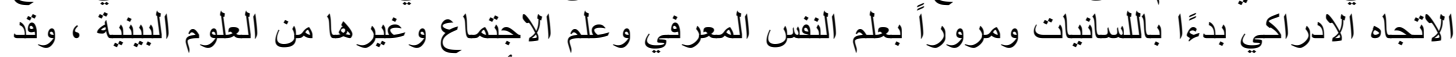

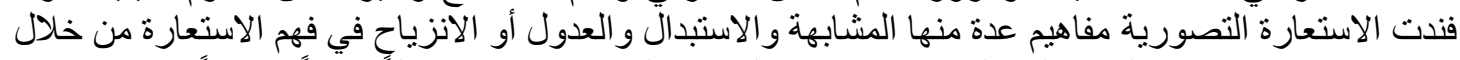

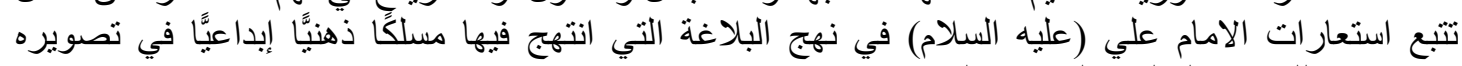

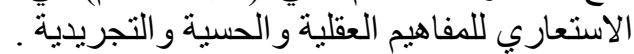

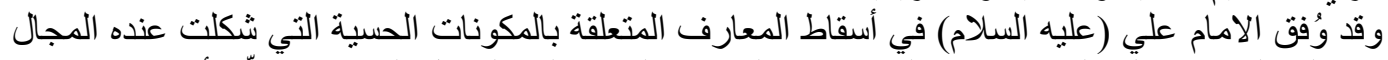

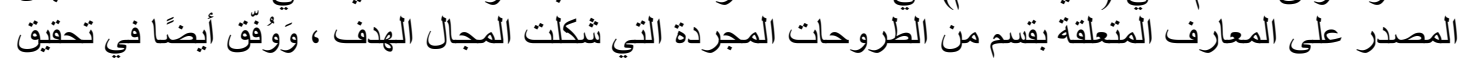
هذه المعادلة الإدر اكية بين المجالين في خطاب النهج.

1- إنَّج التنشئة الدينية للإمام علي (عليه السلام) شكلت ثقافته الموسو عية المتنو عة المشارب الفكرية والمعرفية

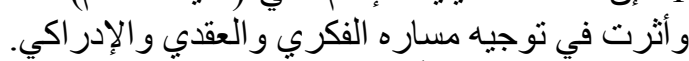

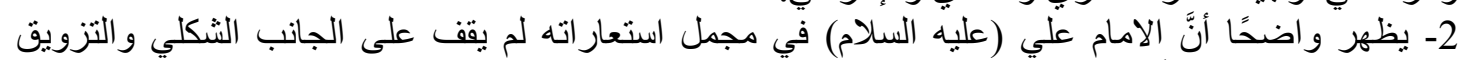

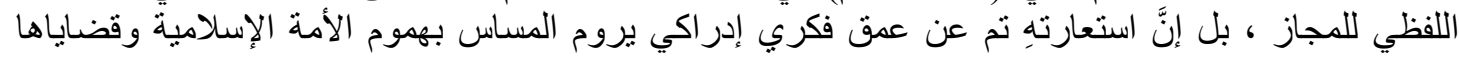

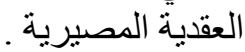

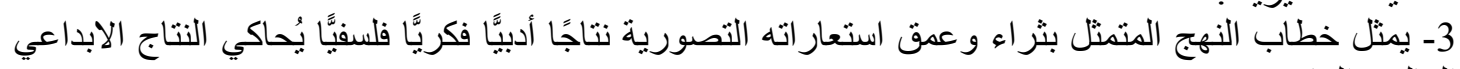

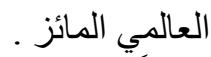
4- إنَّ خطاب نهج البلاغة انسم بالثراء الأسلوبي و البياني الادر اكي الغني بالمفاهيم الادر اكية الحديثة التي تتطلب

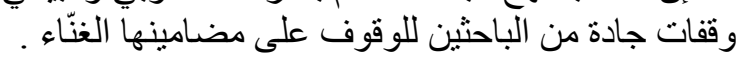




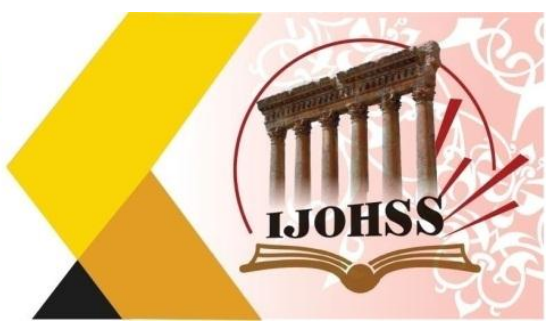

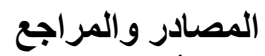

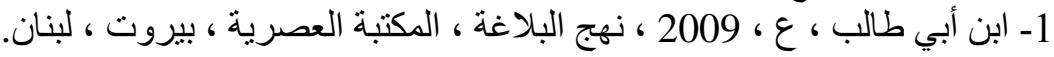

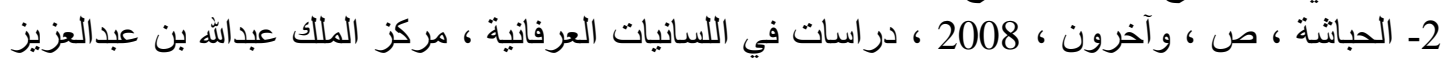
الدولي لخدمة اللغة العربية ، ط المبر 1 ، المملكة العربية السعودية. 3- الحر اصي ، ع ع ، 2003 ، دراسات في الاستعارة المفهومية ، مؤسسة عُمان للصحافة و النشر و الاعلان ، ط 3 3، مسقط ، عُمان.

4- الزيتوني ، كُ ، و وآخرون ، 2018 ، النص و والخطاب في المباحث العرفانية ، دار كنوز المعرفة ، ط 1 ، عمّان ، الأردن.

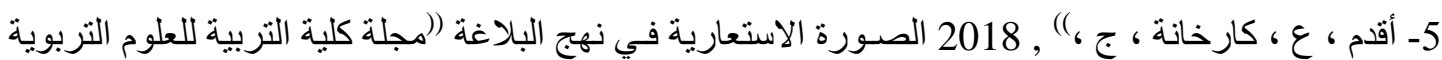

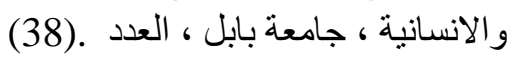
6- بوبوفا ، ز ، وستيرنين ، ي ، 2012 ، اللسانيات الادر اكية ، تر : عزيز ، ث ، بيت الحكمة العر اقي ، ط 1 ،

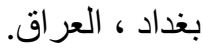

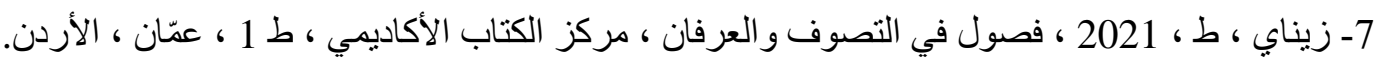

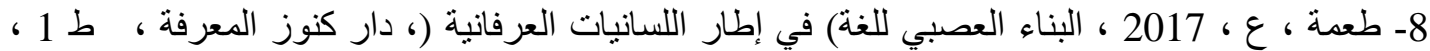

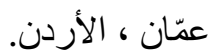
9ـ لَّكوف ، ج ، ، الاردن ، 2014 ، النظرية المعاصرة في الاستعارة ، تر : النعمان ، ط ، مكتبة الاسكندرية ، الاسكندرية

10- لَّكوف ، ج ، جونسن ، م ، 1996 ، الاستعار ات التي نحيا بها : تر : جحفة ، ع ، دار نوبقال ، ط 1 ،

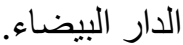

11- لَيكوف ، ج ج ، جونسن ، م ، 2016 ، ، الفلسفة في الجسد) الذهن المتجسد وتحديه للفكر الغربي (، تر ج جحفة

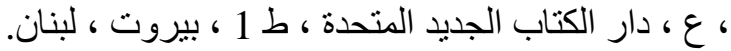

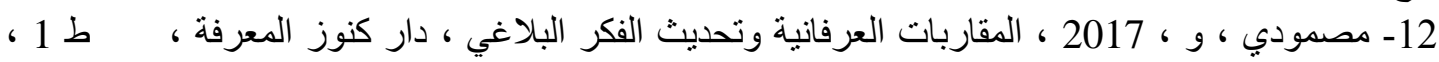

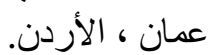

13- نرليش ، ب ، ، كلارك ، ، د ، ، 2017 ،) اللسانيات الادر اكية وتاريخ اللسانيات ((، تر :علوي ، ح ، أنساق :

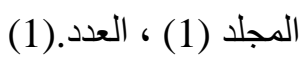

14- هو انغ ، ي ، 2020 ، معجم اكسفورد للتداولية ، تر : خليفة ، هـ ، دار الكتاب الجديد المتحدة ، ط 1 ، بيروت ، لبنان. 15- جاكندوف ، ، ، ، 2010 ، علم الدلالة والعرفانية ، نر : بنور ، ع ، المركز الوطني للترجمة ، تونس. 


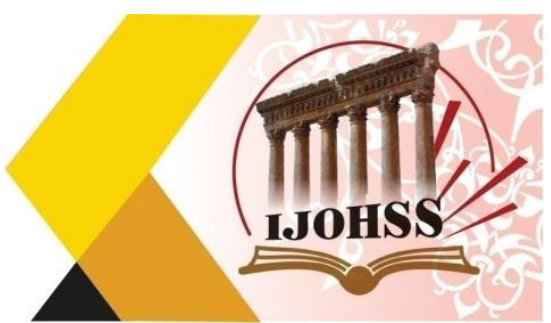

\section{References}

1- Ibn Abi Talib, A, 2009, Nahj al-Balaghah, Al-Maktaba al-Asriyya, Beirut, Lebanon.

2- Al-Habasha, S, et al., 2008, Studies in Gnostic Linguistics, King Abdullah bin Abdulaziz International Center for Arabic Language Service, 1st Edition, Kingdom of Saudi Arabia.

3- Al-Harassi, A., 2003, Studies in Conceptual Metaphor, Oman Corporation for Press, Publishing and Advertising, 3rd Edition, Muscat, Oman.

4- Al-Zaytouni, K, et al., 2018, Text and Discourse in the Divine Investigations, Dar Kunouz Al-Maarifa, 1st Edition, Amman, Jordan.

5- Aqdam, A., Karkhana, C, 2018, ((Metaphorical Image in Nahj Al-Balaghah)) Journal of the College of Education for Educational and Human Sciences, University of Babylon, No. (38).)

6- Popova, Z, and Sternen, J, 2012, Cognitive Linguistics, T.: Aziz, T., The Iraqi House of Wisdom, 1st Edition, Baghdad, Iraq.

7- Zenai, I, 2021, Chapters on Sufism and Gnostic, Academic Book Center, 1st Edition, Amman, Jordan.

8- Tohme, A., 2017, The neural structure of language (in the context of mystical linguistics), Dar Kunouz al-Ma'rifa, 1st Edition, Amman, Jordan.

9- Lykov, J., 2014, Contemporary Theory of Metaphor, see: Al-Numan, I, Bibliotheca Alexandrina, Alexandria, Egypt.

10- Lykoff, J., Johnson, M., Philosophy in the Flesh (The Embodied Mind and Its Challenge to Western Thought), see: Jahfa, A., New United Book House, Volume 1, Beirut, Lebanon.

11- Masmoudi, W, 2017, Mystical Approaches and the Modernization of Rhetorical Thought, Dar Kunouz al-Maarifa, 1st Edition, Amman, Jordan.

12- Narlich, B, Clark, D, 2017, ((Cognitive Linguistics and History of Linguistics)), Tar: Alawi, H, Ansaq: Volume (1), Number (1).

13- Huang, Y, 2020, Oxford Dictionary of Pragmatics, tr: Khalifa, H, United New Book House, 1st Edition, Beirut, Lebanon. 